\title{
The Brake System and Method of the Small Vertical Axis
}

\author{
Wind Turbine \\ Qiuyun Mo ${ }^{1, \mathrm{a}}$, Jiazhe Wen ${ }^{1, \mathrm{~b}}$, Xichang Liu ${ }^{1, \mathrm{c}}$ and Jingyao Wang ${ }^{1, \mathrm{~d}}$ \\ ${ }^{1}$ Guilin University of Electronic Technology, Guangxi, China \\ a2310063352@qq.com, ${ }^{b} 1942198451 @ q q . c o m,{ }^{c} 1475210678 @ q q . c o m$, \\ d550533122@qq.com
}

Keywords: wind power generation; mechanical braking; electromagnetic braking; current detection Abstract: In view of the traditional brake system and method exists the problems of the impact on wind power system is too serious and power generation efficiency is too low, this paper provides a kind of brake system and method that can improve the power generation efficiency and service life of wind power system. Add a current detection circuit in the brake system, current detection circuit is used for detects at least one phase short circuit current value of three-phase armature windings, and pass the current signal to the controller to control use and release of mechanical braking and electromagnetic braking. Analyzes the braking principle of mechanical and electromagnetic brake, and the method of improved braking system, the improved braking system makes the rotate speed of wind turbine manageable, improved the power generation efficiency, stability and service life of the wind power generation system effectively.

\section{Introduction}

The principle of wind power generation is utilize wind power to drive wind wheel rotating, the wind turbine makes the kinetic energy of wind transform into rotational kinetic energy, and the generator transform the rotational kinetic energy into electrical energy, then output the power to electrical equipment. Firstly, when the wind is very strong, due to the wind wheel speed is too high, wind turbine output more than the rated voltage, and it is likely the output voltage is too high to damage the electrical equipment ${ }^{[1]}$; Secondly, wind turbines are generally scattered distribution, unattended and remote monitoring ${ }^{[2]}$. Based on the above two points, it can be seen braking system is crucial adjective for wind power system, so requires the braking system has better reliability and security.

When wind speed is too high at a certain moment, the traditional wind turbines braking system use the brake disk and electromagnetic braking at the same time firstly to achieve the braking effect , then release the brake disk and electromagnetic braking at the same time, and through detect the rotate speed, voltage and other ways to judging whether the wind speed is still too high, Using and releasing the brake disk and electromagnetic braking at the same time may generate problems such as wind turbine over speed, circuit overvoltage, brake disk wears serious, wind turbine vibration , they have serious impact on the entire system and affect the stability and service life of wind power system $^{[3]}$. For this purpose, in this paper, adding a current detection circuit in the braking system, it used for detects current value real-time in maintaining electromagnetic braking and passing the current signal to the controller, then the controller controls the use and release order of mechanical 
braking and electromagnetic braking, it avoids the risk of the shocking wind power system serious when use the brake disk and electromagnetic brake again in traditional technology. Improved braking system solves the above problems effectively, at the same time, increasing the utilization rate of wind power.

\section{Small vertical axis wind turbine braking system}

The traditional braking system exist the risk of serious impact on the entire system, and affects the stability and service life of the wind power system ${ }^{[4]}$. Improved wind power generation braking system increase a current detection circuit based on the traditional braking, the current detection circuit detects current value real-time in maintaining electromagnetic braking, then passed the current signal to the controller, the improved wind power generation braking system avoid the risk of impact on the whole system effectively when braking and improve the utilization rate of wind power. Figure 1 is the implementation schematic diagram of improvement wind turbine braking system in this article.

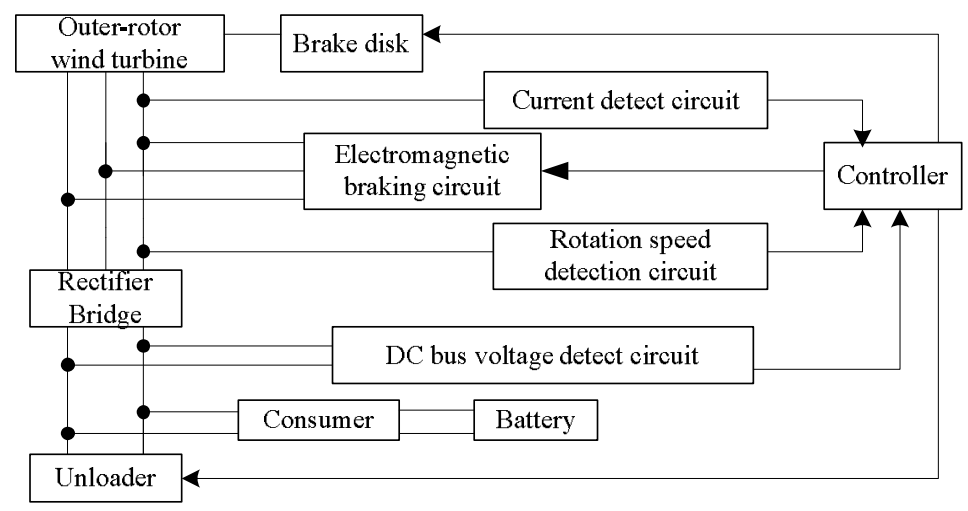

Fig. 1 Schematic diagram of the improved braking system of wind turbine

This article adopted the outer-rotor wind turbine, its blades installed on the shell of generator directly, without other transmission device between generator and blades and make full use of wind energy ${ }^{[5]}$. Blades converted wind energy to outer-rotor rotational kinetic energy, and generator converted outer-rotor rotational kinetic energy into electrical energy. Brakes disk is belong to mechanical braking, make the wind turbine braking by mechanical way; electromagnetic braking circuit belongs to electromagnetic braking, make the wind turbine braking by electromagnetic braking way. Rotating speed detection circuit through detects the generator speed by measurement any one phase voltage of three-phase armature winding when crossing the zero point of the generator, then pass the rotate speed signal to the controller; DC bus voltage detection circuit used for detects the DC voltage in DC bus that the electric energy produced by wind turbines through the rectifier bridge, the detected voltage signal pass to the controller. Controller are instruction devices used to receive the current detecting signal, rotation speed detecting signal and DC bus voltage detecting signal, and control the controlled object (for example, the unloading device, braking disk and electromagnetic braking circuit) according to the scheduled program after these signals are processed and calculated. Rectifier bridge are components seal by rectifier tube and convert alternating current to direct current ${ }^{[6]}$; Electricity consumer provide the electrical energy to users after rectification and adjusted by the power line, at the same time, it charges for the battery; As an energy storage element, battery used to store up the extra power from the electricity generation of generator , and used for provide power for braking disk, at the same time, when long time no wind power and electric power output, the battery can be used as a backup power to supply for electrical equipment ${ }^{[7]}$. Unloading device including resistance and switch (such as relay, contactor, MOS 
tubes, IGBT) and so on, Firstly, it use resistance to consume the excess power generated by wind turbine; Secondly, the unloading current in unloading device would produce counter electromotive force and counter torque in three-phase armature winding of the generator, so it has braking effect to speed of generator and wind wheel, it can achieve better braking effect when the unloading device input full power ${ }^{[8]}$.

Unlike traditional braking system, improved braking system increased a current detection circuits, it used for detects at least one phase short circuit current value of wind turbine three-phase armature winding. Figure 2 shows the diagram of current detection circuit .Including current detection element and sampling resistance, the current detection element preferred choose hall element or current transformer. The current detection circuits concatenated between generators and electromagnetic brake circuit and links to at least one phase in the three-phase armature windings. Sampling resistance concatenated in the output of the current detection element, it produce voltage that linearly proportional with current on the sampling resistor, the voltage signal converted into the voltage that can accepted by the controller after linear scaling or other processing. Current detection circuit also can use sampling resistance sampling the current directly, but preferred to choose hall element or current transformer or other isolation test components to test after signal isolation, so as to avoid the interference between each other.

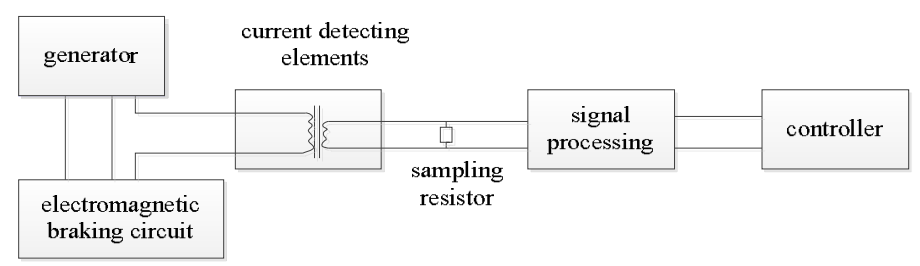

Fig. 2 Schematic diagram of current detecting circuit

\section{The mechanical and electromagnetic braking principle of small vertical axis wind turbine}

\section{Mechanical braking principle}

The current application of the mechanical braking include brake disk and hydraulic brake, this paper adopt the brake disk to mechanical braking for the system, it selects the flange single plate electromagnetic brakes, it produce electromagnetic pressure on the brake disk, through produce friction on the brake disk surface to make the brake disk deceleration, and produce braking effects to wind power system, its basic structure is shown in figure 3 .

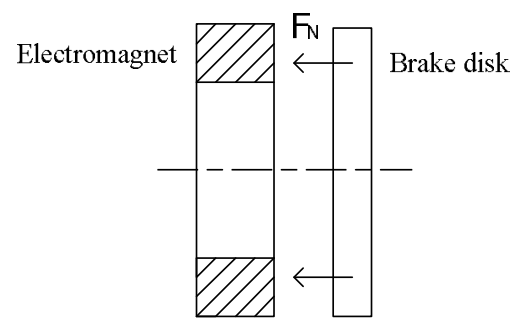

Fig.3 force of the brake

\section{Electromagnetic braking principle}

Electromagnetic braking achieve braking effect through braking torque that generated by electromagnetic induction of generator, it is a kind of non-contact way, thus, there are various negative effects caused by friction in mechanical braking ,but did not exist in the electromagnetic braking. This paper adopts electromagnetic braking way which three-phase armature winding 
short-circuit, its advantage is wiring simple, good braking effect in low speed region. The connection of three-phase armature winding braking way as shown in figure 4.

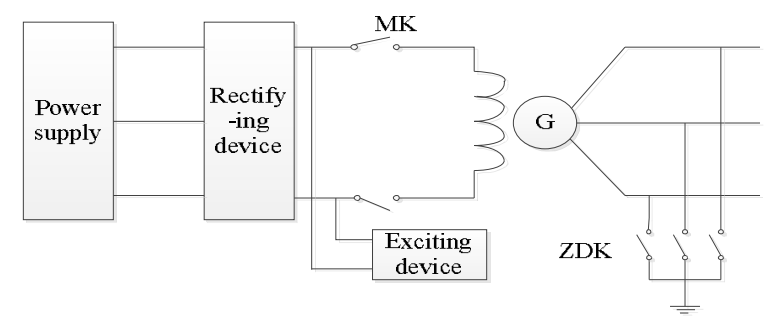

Fig.4 Schematic diagram of three-phase armature winding braking

Outer-rotor wind turbine though impeller absorbed energy to drive the rotor rotation, the generator armature winding may produce induced current, When the wind speed is too fast ,the controller receives the corresponding signal and sends control command, it would to closed the short circuit switch ZDK and excitation switch MK to input exciting current for exciting winding, it will form the three-phase short-circuit current in the stator winding, called braking current, the braking current will produce counter torque and make the impeller and rotor deceleration ${ }^{[9]}$.through adjusting the excitation current, can adjust the value of the braking current, and the braking torque is along with the changes of braking current, but in order to not generate excessive heat on stator, ordinarily, braking current is around the rated current, no more than 1.2 times rated current ${ }^{[10]}$.

\section{Improved braking method of small vertical axis wind turbine}

\section{Control process of improved braking system}

Improved braking system of wind turbine increase a current detection circuit, the brake control process is: when at a certain time, the rotor speed increases as the wind speed increases, and the DC bus voltage increases, the rotate speed detection circuit would detected the rotating speed has increased, the DC bus voltage detection circuit would detected the DC bus voltage also has increased, the test signals pass to the control system, If the DC bus voltage detection signal of voltage and rotate speed detection signal of rotational speed accepted by controller are no more than the brake setting value, it would not take any action. If any value of voltage or speed accepted by controller are more than the set value, which is the power of wind turbines absorbed more than the consumption power, so the controller will connect unloading device switch firstly, and make the unloading device full power to work, it makes the speed of wind turbine reduce to a certain value, the brake disk is in working, a short period of time (such as 1 second) after brake disk start work, the electromagnetic brake start work. At this time, the rotation speed has been down, and then release the brake disk and unloading device in turn, but still keep the electromagnetic brake. At this point, the first stage of improved braking method is end. The first phase schematic flow diagram of improved braking method is shown in figure 5 .

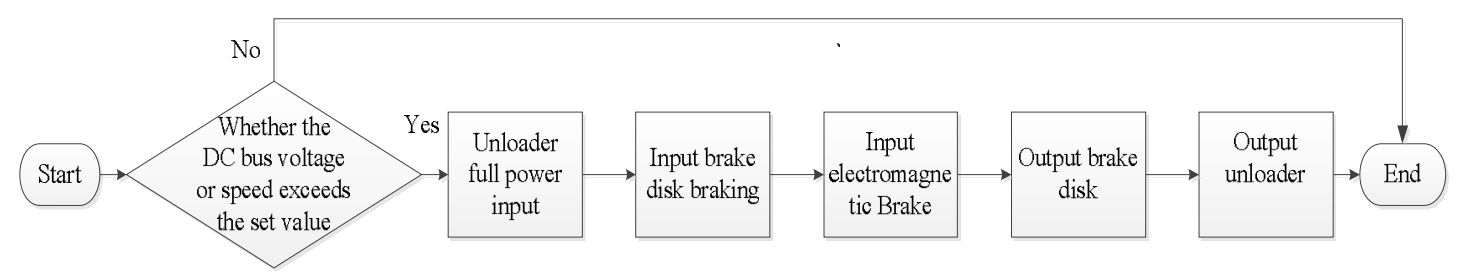

Fig.5 Schematic flow chart of the first phase of the improved braking method

After the first phase of the braking process, the current detection circuit detects the any of phase short-circuit current value real-time of three-phase armature winding in the process of 
electromagnetic braking. The detection signal is passed to the controller, the controller judges whether the detection current value was exceeds the maximum allowed short-circuit current $\mathrm{I}_{\max }$, if more than the maximum permissible short circuit current, that shows the wind speed remains fast, the speed of wind wheel rising again, three-phase armature winding has danger of destroyed, input the brake disk immediately at this time, it continue a period of time of brake disk and then exit. If the controller judged the current did not exceed the maximum allowable short circuit current of wind turbines, then continue to judges whether the detection current is more than normal working current of generator $I_{\text {norm }}$ (rated current), the rated current should be less than the maximum permissible short circuit current. If testing current exceeds the normal working current, remain the electromagnetic braking state, However, if it is no more than normal working current, so released the electromagnetic braking, the generator get into the normal state of power generation. At this point, the second stage of improved braking method is end. The second stage signal flow chart of improved braking method is shown in figure 6 .

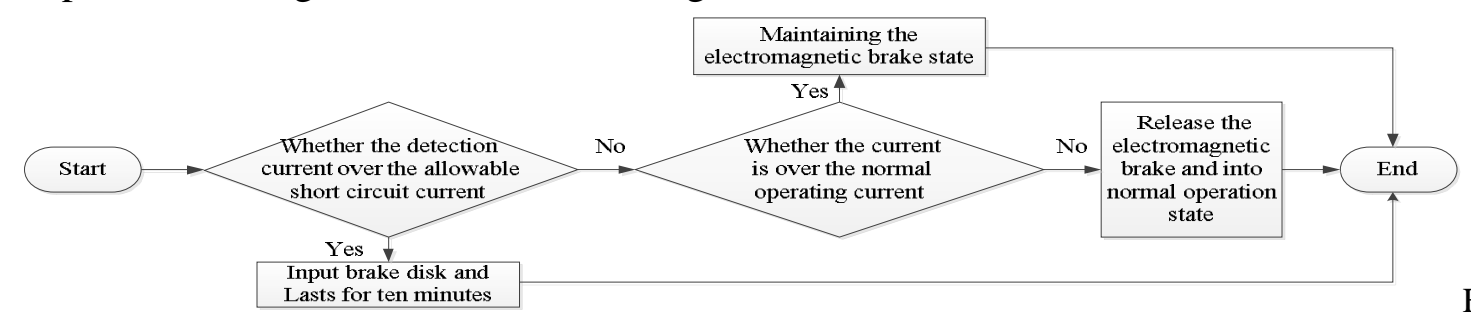

Fig.6 Schematic

flow chart of the second stage of the improved braking method

\section{Feasibility analysis of improved braking method}

When encountered strong winds at a certain moment, traditional brake system of wind turbine input the brake disk and electromagnetic brake at the same time to reach braking effect of the system, then release the brake disc and electromagnetic braking at the same time, and through detects the rotate speed, voltage and other ways to judging whether the wind speed is still too high, if the wind speed is still too high, put the brake disc and electromagnetic braking at the same time again, it requires constant longer setting time for braking now. Thus makes the wind turbine over speed, circuit overvoltage, brake disk wear, wind turbine vibration, etc., and the brake disk braking energy is from the power of battery. As a result, if the strong wind appeared and continued a long time, the traditional braking system and method have serious impact and large energy consumption on the whole system, it reduce effective utilization of clean energy and influence the stability and lifetime of the wind power.

Based on the above shortcomings of traditional braking method, this paper provides an improved braking system and method. Compared with the traditional braking system and method, the improved wind power generation system and the method add a current detection circuit and bring the following technological effects. Firstly, due to the braking system added current detection circuit, it detects the three-phase armature winding short-circuit current real-time of generator, and judgement the wind speed value when not release electromagnetic braking. Transfer testing current signal to the controller, the controller execute corresponding braking operation based on the analysis, so need not release the brake disc and electromagnetic brake at the same time to detect rotate speed like the traditional technology. Secondly, because have not release electromagnetic brake in the brake process, so, the speed of wind wheel is controllable, it avoids the shock risk to wind system of due to put the brake disk and electromagnetic brake again at the same time in traditional technology. Thirdly, it can monitor three-phase short-circuit current real-time and judging the value of wind speed, so not need long time to maintain the mechanical brake and consumes electricity. But also release the brakes in time to let generator normal power as soon as 
possible according to the value of wind speed, it improved the effective utilization of the wind power system and power generation efficiency ${ }^{[11]}$.

\section{Conclusion}

Because of inhomogeneity distribution and atrocious running environment of wind turbines, it requires the braking system has higher reliability and security. The traditional braking system have low power generation efficiency and exist the impact risk of wind power in the process of braking when input the brake disc and electromagnetic brake at the same time. This article provides an improved wind power generator braking system and method which increased a current detection circuit in the braking system, through detects at least one phase short circuit current value real-time of three-phase armature windings, then pass the detection signals to controller, the controller control input and release the brake disk and electromagnetic braking based on signal processing. Improved braking system maintain the electromagnetic braking state, so the speed of wind wheel becomes manageable, it avoids the deficiencies effectively of traditional braking system, and improved the generating efficiency, stability and service life of the wind power generation system.

\section{Acknowledgements}

This work was financially supported by National Natural Science Foundation (51465010), Guangxi Manufacturing Systems and Advanced Manufacturing Technology Key Laboratory of the Subject (14-045-15-010Z), Hundreds of Billions Industry of Key Technology Research Project of Guangxi (12118020-1-4).

\section{Reference}

[1]Wang Wenliang, Ge Baoming, Bi Daqiang. Direct drive permanent magnet synchronous of energy storage wind power generation control system $[\mathrm{J}]$. Power system protection and control. $2010,38$ ( 14$): 43-48,78$.

[2] Song Haihui. Wind power technology and engineering [M]. Beijing: Water Conservancy and Hydropower Press of China, 2009

[3] Ye Hangzhi. Control technology of wind turbine [M]. Beijing: Mechanical Industry Press, 2012

[4] Shi Shanshan. The turnaround trend of wind industry is expected continue and wind power companies need more research[J]. power system equipment,2014,(8) : 73-74

[5] Ren Shaohua. Research on permanent magnet brushless of double rotor wind turbine[D]. Tianjin: Hebei University of Technology, 2011

[6] Wang Zhaoan, Huang Jun. Electric power electronic technology [M]. Beijing: Beijing Industry Press, 2000

[7] Zhou Zhimin, Zhou Jihai, Ji Aihua. Practical technology of valve controlled sealed lead acid battery [M]. Beijing: China Electric Power Press, 2004

[8] Guo Mingxia, Yang Jinming. Power electronic technology and control technology in wind power [J]. China water transport, 2007, 17(3): 70-73

[9] Li Shaoying. Research on AC excitation control technology of wind turbine[D]. Tianjin. Hebei University of Technology, 2011,22-23

[10] Qiao Zhaoying. Research on independent small wind power generator and its controller[D]. Shanxi: Xi'an University of Science and Technology, 2008 
[11] Su Shaoyu. Operation and maintenance of wind turbine[M]. Beijing: China electric power press 